OPEN ACCESS

Edited by:

Peter Flatt,

Ulster University, United Kingdom

Reviewed by:

Aileen King,

King's College London,

United Kingdom

Finbarr P. M. O'Harte,

Ulster University, United Kingdom

Steven Patterson,

Glasgow Caledonian University,

United Kingdom

*Correspondence: Hannelouise Kissow

kissow@sund.ku.dk

Specialty section: This article was submitted to

Gut Endocrinology,

a section of the journal

Frontiers in Endocrinology

Received: 11 December 2020

Accepted: 19 January 2021

Published: 26 February 2021

Citation:

Hunt JE, Hartmann B, Schoonjans K, Holst JJ and Kissow H (2021) Dietary

Fiber Is Essential to Maintain Intestinal Size, L-Cell Secretion, and Intestinal Integrity in Mice.

Front. Endocrinol. 12:640602. doi: 10.3389/fendo.2021.640602

\section{Dietary Fiber Is Essential to Maintain Intestinal Size, L-Cell Secretion, and Intestinal Integrity in Mice}

\author{
Jenna Elizabeth Hunt ${ }^{1,2}$, Bolette Hartmann ${ }^{1,2}$, Kristina Schoonjans ${ }^{3}$, Jens Juul Holst ${ }^{1,2}$ \\ and Hannelouise Kissow ${ }^{1,2 *}$ \\ ${ }^{1}$ Department of Biomedical Sciences, Faculty of Health and Medical Sciences, University of Copenhagen, Copenhagen, \\ Denmark, ${ }^{2}$ Novo Nordisk Foundation Center for Basic Metabolic Research, Faculty of Health and Medical Sciences, \\ University of Copenhagen, Copenhagen, Denmark, ${ }^{3}$ Institute of Bioengineering, School of Life Sciences, École Polytechnique \\ Fédérale de Lausanne, Lausanne, Switzerland
}

Dietary fiber has been linked to improved gut health, yet the mechanisms behind this association remain poorly understood. One proposed mechanism is through its influence on the secretion of gut hormones, including glucagon-like peptide-1 (GLP-1) and glucagon-like peptide-2 (GLP-2). We aimed to: 1) investigate the impact of a fiber deficient diet on the intestinal morphological homeostasis; 2) evaluate L-cell secretion; and 3) to ascertain the role of GLP-1, GLP-2 and Takeda G protein-receptor-5 (TGR5) signaling in the response using GLP-1 receptor, GLP-2 receptor and TGR5 knockout mice. Female C57BL/6JRj mice $(n=8)$ either received a standard chow diet or were switched to a crude fiber-deficient diet for a short (21 days) and long (112 days) study period. Subsequent identical experiments were performed in GLP-1 receptor, GLP-2 receptor and TGR5 knockout mice. The removal of fiber from the diet for 21 days resulted in a decrease in small intestinal weight $(p<0.01)$ and a corresponding decrease in intestinal crypt depth in the duodenum, jejunum and ileum $(p<0.001, p<0.05$, and $p<$ 0.01 , respectively). Additionally, colon weight was decreased $(p<0.01)$. These changes were associated with a decrease in extractable GLP-1, GLP-2 and PYY in the colon ( $p<$ $0.05, p<0.01$, and $p<0.01$ ). However, we could not show that the fiber-dependent size decrease was dependent on GLP-1 receptor, GLP-2 receptor or TGR5 signaling. Intestinal permeability was increased following the removal of fiber for 112 days. In conclusion, our study highlights the importance of dietary fiber to maintain intestinal weight, colonic L-cell secretion and intestinal integrity.

Keywords: dietary fiber, GLP-2, GLP-1, TGR5 (GPBAR1), L-cell

\section{INTRODUCTION}

Non-digestible carbohydrates, termed dietary fibers, have been linked to improved health outcome, especially concerning gut health (1). Their presence in the diet can delay gastric emptying rate (2), increase fecal bulk and moisture content (3), and impact bacterial diversity (4) and fermentation (5). Despite these attributes, fiber consumption in the diets of westernized nations continues to fall 
below the recommended guidelines (6). This 'western diet' is characterized by calorie-rich processed foods, high in sucrose and saturated fats with reduced dietary fiber (7) and is linked to the rise in noncommunicable diseases (1) and a decrease in microbial diversity $(8,9)$. Additionally, low fiber diets are recommended to patients to manage intestinal symptoms such as diarrhea in a range of gastrointestinal conditions including Crohn's disease, ulcerative colitis, irritable bowel syndrome, as well as following chemotherapy and radiotherapy (10). One proposed mechanism by which diet composition can influence health is through its influence on the secretion of gut hormones, including glucagon-like peptide-1 (GLP-1) and glucagon-like peptide-2 (GLP-2) $(11,12)$. The glucagon-like peptides are cosecreted from enteroendocrine L-cells, predominantly located in the distal small intestine (SI) and colon. GLP-1 is a multifunctional incretin hormone best known for modulating glucose metabolism (13) but also has a mild trophic effect in the intestine of rodents $(14,15)$. GLP-2 plays an important role in gut epithelium function by being the major regulator of the intestinal size as well as absorptive capacity (16-19). Together GLP-1 and GLP-2, synergistically ameliorate intestinal injury and improve intestinal healing (20).

Classically, luminal nutrient delivery has been described as the stimulus for enteroendocrine L-cells (21), but more recently other stimuli such as short-chain fatty acids (SCFA) and bile acids have also been reported to be stimulators in experimental animals $(22,23)$ and humans $(24,25)$. SCFAs are the primary fermentation products of dietary fiber by bacteria located in the proximal colon (26) and exert their secretagogue function by binding to the free fatty acid receptors 2 and 3 (FFAR2 and FFAR3) located on L-cells $(27,28)$. The gut microbiota metabolizes and modifies bile acids and regulates the expression of their synthesizing enzymes (29, 30). They exert their secretagogue function by binding to the bile acid receptor Takeda G protein-receptor-5 (TGR5) located on intestinal Lcells (31).

Given the ability of dietary fiber to modulate the gut microbiota (5) and its fermentation products we hypothesized that the removal of dietary fiber would decrease the gut size and available absorptive capacity due to the moderation in L-cell secretion. We aimed to investigate the impact of a fiber deficient diet on the intestinal morphological homeostasis and L-cell secretion and to evaluate GLP-1 receptor (GLP-1r), GLP-2 receptor (GLP-2r) and TGR5 signaling in the response using knockout mice.

\section{MATERIALS AND METHODS}

\section{Animals}

All experiments adhered to guidelines of Danish legislation governing animal experimentation (1987) and were approved by the Danish animal experiments inspectorate (license no. 2013-15-2934-00833). Female C57BL/6JRj mice, 8 weeks of age, were purchased from Janvier Laboratories, Saint-Berthevin Cedex, France. Female GLP-1r knockout mice $\left(G L P-1 r^{-/}\right)$, 8-12 weeks of age, were generated using the loxP/Cre system as described previously (32). Female GLP-2r knockout mice $\left(G L P-2 r^{-/}\right), 8-12$ weeks of age, were generated via CRISPR/ Cas9-mediated gene editing as described previously (33). Female TGR5 knockout mice (TGR $5^{-/}$), 8-12 weeks of age, were bred inhouse with permission from the Laboratory of Integrative and Systems Physiology, Ecole Polytechnique de Lausanne, Switzerland (34). All knockout mice were bred by heterozygote breeding and GLP-1r $r^{+/+}, G L P-2 r^{+/+}$and $T G R 5^{+/+}$littermates were used as controls. All animals were housed in the same animal facility under standard 12:12 h light-dark cycles with ad libitum access to food and water.

\section{Experimental Setup}

\section{Fiber-Free Diet in C57BL/6JRj Mice}

Female mice $(n=8)$, housed 8 per cage, either continued to receive a standard chow diet herein referred to as 'chow' (Altromin, Lage, Germany, cat.no. 1310) or were switched to a crude fiber-deficient diet (Altromin, cat.no. 1013) referred herein to as 'fiber-free' for 21 or 112 days (Table 1; for full nutritional composition, see Supplementary Data Table 1 https://doi.org/ 10.6084/m9.figshare.13568261.v1). All animals from the 21 days experiment were weighed every four days and their daily food intake was determined by hand weighing the remaining food per cage. Daily nutritional consumption per mouse was calculated by dividing the total intake ( $\mathrm{g}$ ) per cage by the number of mice in the cage, multiplied by the macronutrient distribution of the diets per g (Figure 1).

Mice were given an intraperitoneal injection of bromodeoxyuridine (BrdU) $(50 \mathrm{mg} / \mathrm{kg}$ ) (Sigma-Aldrich, Missouri, US, cat.no. B5002) (only the 21 days experiment) and an oral gavage of fluorescein isothiocyanate dextran (FITC-dextran) (400 mg/kg) (Sigma-Aldrich, cat.no. 60842-468) $2 \mathrm{~h}$ before sacrifice. Mice were anesthetized with an intraperitoneal injection of ketamine (90 mg/kg) (MSD Animal Health, Madison, New Jersey, US, cat.no. 511485) and xylazine (10 mg/kg) (Rompun Vet, Bayer Animal Health, Leverkusen, Germany, cat.no. 148999). From a midline incision, a total blood draw was made from the vena cava and the blood was collected in pre-cooled $3.9 \mathrm{mmol} / \mathrm{l}$ EDTA-coated tubes (Eppendorf, Hamburg, Germany, cat.no. 20901-757) and stored on ice until centrifuged $\left(3500 \mathrm{rpm}, 15 \mathrm{~min}, 4^{\circ} \mathrm{C}\right)$. Plasma was transferred to pre-cooled Eppendorfs and stored at $-20^{\circ} \mathrm{C}$ until further analysis. The small intestine (SI) was resected and partitioned into the duodenum, jejunum and ileum and the colon was resected. All the resected tissue was flushed and weighed as previously described (35). Transverse sections of the duodenum, jejunum, ileum and colon were fixed in $10 \%$ neutral formalin buffer for

TABLE 1 | Nutritional composition of diets per g/100 g.

\begin{tabular}{lcc}
\hline Group & Fiber-free & Chow \\
\hline Fiber & 0.17 & 6.10 \\
Fat & 5.08 & 4.10 \\
Protein & 17.61 & 19.20 \\
Carbohydrate & 62.19 & 40.80 \\
kcal/kg & 3670.06 & 3188.00
\end{tabular}



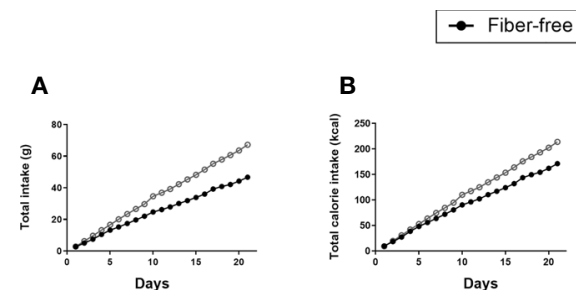

$\rightarrow$ Chow

FIGURE 1 | Dietary intake and body weight change in C57BL/6JRj mice fed a fiber-free diet for 21 days. (A) Total dietary intake calculated by dividing the total food intake (g) per cage by the number of mice in the cage. (B) Total calories consumed per mouse. (C) Body weight (BW). (D) Change in be BW expressed as percentage BW change from day 0. BW and change in BW was compared using a two-way ANOVA followed by a Sidak's multiple comparisons test and data are presented as mean \pm SEM. ${ }^{*} p<0.05,{ }^{* *} p<0.01$, and ${ }^{\star \star * *} p<0.0001$.

$24 \mathrm{~h}$ and subsequently transferred to $70 \%$ ethanol until further processing for histology and immunohistochemistry (IHC). Additional tissue samples were collected in the same manner, then snap-frozen and stored at $-80^{\circ} \mathrm{C}$ until protein extraction and radioimmunoassay (RIA) (only 21 days).

\section{Fiber-Free Diet in Knockout Mice}

Female GLP-1r $r^{-/}$, GLP-2r-/- and TGR5 ${ }^{-/-}(\mathrm{n}=8-10)$ mice and their $G L P-1 r^{+/+}, G L P-2 r^{+/+}$and $T G R 5^{+/+}$littermates $(\mathrm{n}=8-10)$ either continued to receive the chow diet (Altromin, cat.no. 1310) or were switched to the fiber-free diet (Altromin, cat.no. 1013) for 21 days. All animals were weighed every four days and intestines were resected, flushed and weighed as described previously.

\section{Histology}

Formalin-fixed tissue from the duodenum, jejunum, ileum and colon was first dehydrated and paraffin-embedded. Slices of the embedded tissue $(4 \mu \mathrm{m})$ were cut using a microtome (pfm Slide 4005 E, pfm medical, Köln, Germany) and stained with hematoxylin/eosin. The average crypt depth and villus height were approximated by measuring these parameters in 20 welloriented villi and crypts. Mucosa area was measured by subtracting the luminal circumference from the submucosal circumference. All measurements were made from histological photographs taken using a light microscope connected to a camera (Zeiss Axio Lab.A1, Brock \& Michelsen, Birkeroed, Denmark) and Zeiss Zen lite software (Carl Zeiss Microscopy GmbH, Göttingen, Germany) (demonstrated in Supplementary Data Figure 1A https://doi.org/10.6084/m9.figshare.13594058. v1). The observer was blinded as to the origin of the section.

\section{Immunohistochemistry}

Slides were stained using the Ultravision Quanto Detection System HRP DAB (Thermo Fisher Scientific, Massachusetts, US, cat.no TL-060-QHD), according to the manufacturers' instructions and pre-treated by heat-induced epitope retrieval in Tris/EDTA buffer pH 9.0 (Thermo Fisher Scientific, cat.no TA-125-PM4X). Non-specific binding was blocked using Rodent Block Buffer (Ultravision Quanto Mouse on Mouse kit, Thermo Fisher Scientific, cat no. TL-060-QHDM) according to the manufacturers' instructions. The monoclonal mouse anti-BrdU antibody BU20a (Thermo Fisher Scientific, cat.no MA1-81890,
RRID : AB_927209) diluted 1:500 was applied to the tissue for $1 \mathrm{~h}$. Slides were counterstained with hematoxylin and visualized using a light microscope. Proliferation was quantified by counting the total number of crypt cells and calculating the percentage of BrdU positive cells per crypt. At least 20 wellorientated crypts were selected in each section. The observer was blinded as to the origin of the section.

\section{Protein Extraction}

Intestinal tissue was subject to peptide extraction as previously described (33). In short, the tissue samples were homogenized in 1\% trifluoroacetic acid (TFA; Thermo Fisher Scientific, cat.no. TS-28904) then left to stand at room temperature for $1 \mathrm{~h}$ and were then centrifuged for $10 \mathrm{~min}$ at $2000 \mathrm{xg}$. After determination of the concentration of protein (Pierce BCA Protein Assay Kit, Thermo Fisher Scientific, cat.no 23225), the supernatants were fractionated using tc18 cartridges (Waters, Massachusetts, US, cat.no 036810). After evaporation, ethanol-eluted peptides were reconstituted in assay buffer (phosphate buffer $80 \mathrm{mM}, 0.1 \%$ human serum albumin, EDTA $10 \mathrm{mM}, \mathrm{pH} 7.5$, plus $0.01 \mathrm{mM}$ of the dipeptidyl peptidase- 4 inhibitor valine-pyrrolidide).

\section{Radioimmunoassay}

Total concentrations of amidated GLP-1 were quantified using antiserum (code name 89390) targeting the C-terminus of the GLP-1 molecule and reflects the sum of intact GLP-1 (7-36) amide, the primary metabolite GLP-1 (9-36)amide and any other GLP-1(x-36)amide isoforms (36). Intact GLP-2 (1-33) was measured using antiserum (code name 92160) targeting the N-terminus of the GLP-2 molecule (37). Total PYY, sum of 1-36 and 3-36 forms, was quantified using antiserum (code name T-4093) (38). Concentrations were normalized to measured protein content in the extract.

\section{Plasma Determination of FITC-Dextran}

Total intestinal permeability was indirectly measured by the determination of the non-digestible $4-\mathrm{kDa}$ dextran conjugated with fluorescein isothiocyanate (FITC-dextran) in plasma (39). Following oral administration, FITC-dextran transits through the gastrointestinal tract and can passively pass through the intestinal epithelium. The concentration of FITC-dextran in plasma represents the permeability of the intestinal epithelium. Plasma 
was diluted in an equal volume of phosphate-buffered saline (PBS) and subjected to fluorescence analysis using an excitation wavelength of $485 \mathrm{~nm}$ and an emission wavelength of $528 \mathrm{~nm}$ in a SpectraMax iD3 multi-mode microplate reader (Molecular Devices, San Jose, US). The results of the fluorescence measurements were compared to a standard curve of known FITC-dextran concentrations.

\section{Calculation and Statistical Evaluation}

All statistics were performed using GraphPad Prism 6 (La Jolla, California, US). Statistical evaluations of the data were carried out using two-sided, unpaired t tests when comparing two independent groups and a two-way analysis of variance (ANOVA) when comparing multiple independent groups followed by a Sidak's multiple comparisons test. Values of $\mathrm{p}<$ 0.05 were considered significant and all data in the text and graphs were presented as mean \pm SEM.

\section{RESULTS}

\section{Fiber-Free Diet in C57BL/6JRj Mice Dietary Intake and Body Weight}

After the 21 days of feeding, fiber-free fed mice had a lower total intake of diet per mouse (47 vs. $67 \mathrm{~g}$ ) (Figure 1A). This resulted in a lower total calorie intake (171 vs. $214 \mathrm{kcal}$ per mouse) (Figure 1B). Unsurprisingly, total fiber intake after 21 days was lower in the fiber-free group (0.08 vs. $4.11 \mathrm{~g})$. Total fat (2.37 vs. $2.75 \mathrm{~g}$ ) and carbohydrate ( 29 vs. $27 \mathrm{~g}$ ) consumption after 21 days was similar in both treatment groups. Fiber-free mice had a lower total protein intake ( 8 vs. $13 \mathrm{~g}$ ) compared to the chow fed mice after 21 days. Body weight (BW) was significantly decreased from day 17 in the fiber-free mice (Figure 1C) and the percentage BW change was significantly different from day 8 until the end of the study (Figure 1D).

\section{Weight and Morphometric Estimates in the Intestine}

Fiber-free fed mice had significantly reduced intestinal weights, relative to BW, in the duodenum (11\%), the jejunum (28\%) and the ileum (32\%) after 21 days of feeding (Figure 2A). Total small intestine (SI) weight relative to $\mathrm{BW}$, was significantly reduced by 25\% (Figure 2B). Additionally, fiber-free feeding significantly decreased SI weight per length (Figure 2C). Given this, surprisingly fiber-free mice had a significant increase in duodenal villus height (Figure 2D). Villus height in the jejunum and ileum remained unchanged (Figure 2D). Fiberfree feeding significantly reduced crypt depth in the duodenum by $13 \%$, in the jejunum by $36 \%$, and in the ileum by $23 \%$, crypt depth remained unchanged in the colon but the overall mucosa area in the colon was significantly decreased (Figures 2E, F). Images of representative hematoxylin and eosin-stained intestinal tissue are displayed in Supplementary Figures 1B, C; https://doi.org/10.6084/m9.figshare.13594058.v1). Colon weight, relative to BW, was significantly decreased by $41 \%$ (Figure 2G) and colon weight per length was significantly decreased (Figure 2H). Fiber-free feeding did not affect the number of BrdU immunopositive cells per crypt in the SI or colon (Figure 2I).
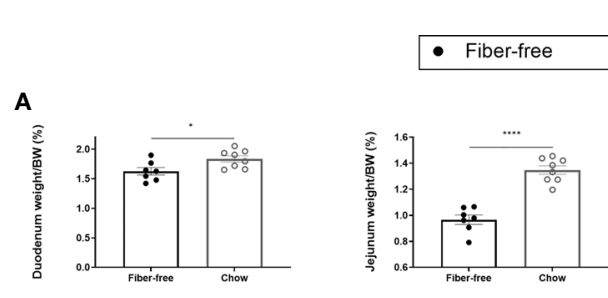

- Chow

C

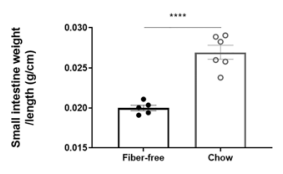

G

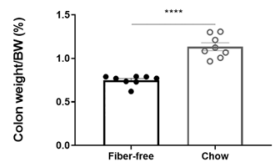

D

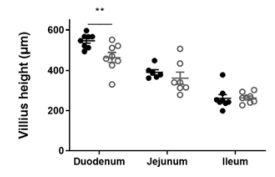

H

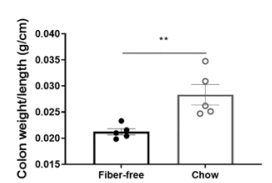

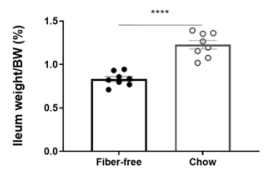

B

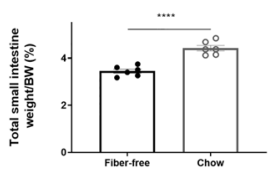

E

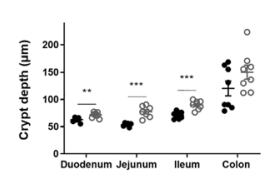

$\mathbf{F}$

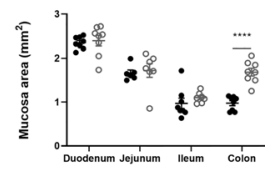

I

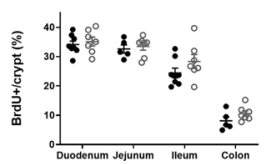

FIGURE 2 | Morphometric estimates in the intestine of C57BL/6JRj mice fed a fiber-free diet for 21 days. Weight of the intestine in mice receiving either a fiber-free or chow diet for 21 days. (A) Duodenum, jejunum and ileum weight relative to final body weight (BW); (B) Total small intestinal (SI) weight relative to BW; (C) SI weight relative to SI length; (D) SI Villus height; (E) SI and colon crypt depth; (F) SI and colon mucosa area; (G) Colon weight relative to BW; (H) Colon weight relative to colon length; (I) BrdU immunopositive (BrdU+) cell number expressed as a percentage of total crypt cell number. Data were compared using a two-sided, unpaired students t-test and presented as mean \pm SEM. ${ }^{\star} \mathrm{p}<0.05,{ }^{\star \star *} \mathrm{p}<0.01,{ }^{\star \star *} \mathrm{p}<0.001,{ }^{\star \star \star *} \mathrm{p}<0.0001$. 
Long-term fiber-free fed mice had significantly reduced intestinal weights, relative to BW, in the duodenum (13\%), the jejunum (29\%) and the ileum (38\%) (Figure 3A). Total SI weight, relative to $\mathrm{BW}$, was significantly reduced by $28 \%$ (Figure 3B) and there was a tendency $(\mathrm{p}=0.0594)$ for reduced SI weight per length (Figure 3C). Fiber-free feeding did not affect the villus height in the duodenum and jejunum, but in the ileum, the villus height was significantly decreased by 19\% (Figure 3D). Fiber-free feeding significantly reduced crypt depth in the duodenum by $28 \%$, in the jejunum by $35 \%$ and in the ileum by $30 \%$ and tended to reduce crypt depth in the colon ( $\mathrm{p}=0.0558)$ (Figure 3E). Mucosa area was significantly decreased in the ileum and colon (Figure 3F). Images of representative hematoxylin and eosin-stained intestinal tissue are displayed in Supplementary Figure 1, panel D and E https://doi.org/10. 6084/m9.figshare.13594058.v1). Colon weight, relative to BW, was significantly decreased by $44 \%$ following a long-term fiberfree diet (Figure 3F). Colon weight per length was significantly decreased in fiber-free mice compared to chow (Figure 3G).

\section{L-Cell Hormone Production}

Fiber-free feeding for 21 days significantly decreased the concentration of total GLP-1, by $37 \%$ and $55 \%$ in the ileum and colon, respectively (Figure 4A). The concentration of intact GLP-2 (1-33) remained unchanged in the ileum but was significantly decreased in the colon by $80 \%$ (Figure 4B). Total PYY, remained unchanged in the ileum but was significantly decreased by $48 \%$ in the colon (Figure 4C).

\section{Intestinal Permeability}

Fiber-free feeding did not affect the level of FITC-dextran in the plasma after 21 days (Figure 5A). After 112 days, the concentration of plasma FITC was significantly tripled in the fiber-free mice compared to chow (Figure 5B).

\section{Fiber-Free Diet in Knockout Mice}

In $G L P-1 r^{-/-}$and GLP-1 $r^{+/+}$mice, genotype did not affect BW change (Figure 6A). Total SI weight, normalized to BW, was significantly increased in the chow fed GLP-1r-/- mice compared to chow $G L P-1 r^{+/+}$with no differences between genotypes found in the fiber-free mice (Figure 6B). Genotype did not affect colon weight normalized to BW (Figure 6C). In GLP-2r-- and GLP$2 r^{+/+}$mice, genotype did not affect BW change, SI or colon weight normalized to BW (Figures 6D-F). Similarly, in the $\mathrm{TGR}^{-/-}$and TGR5 $5^{+/+}$mice, genotype did not affect BW change, SI or colon weight normalized to BW (Figures 6G-I).

\section{DISCUSSION}

This study emphasizes the importance of dietary fiber for maintaining intestinal weight, colonic L-cell secretion and intestinal integrity in mice. We show that the removal of crude fiber from the diet dramatically decreased the intestinal size during both the short (21 days) and long-term (112 days) study periods and, additionally, drastically decreased colonic L-cell hormone content after 21 days. Intestinal permeability was

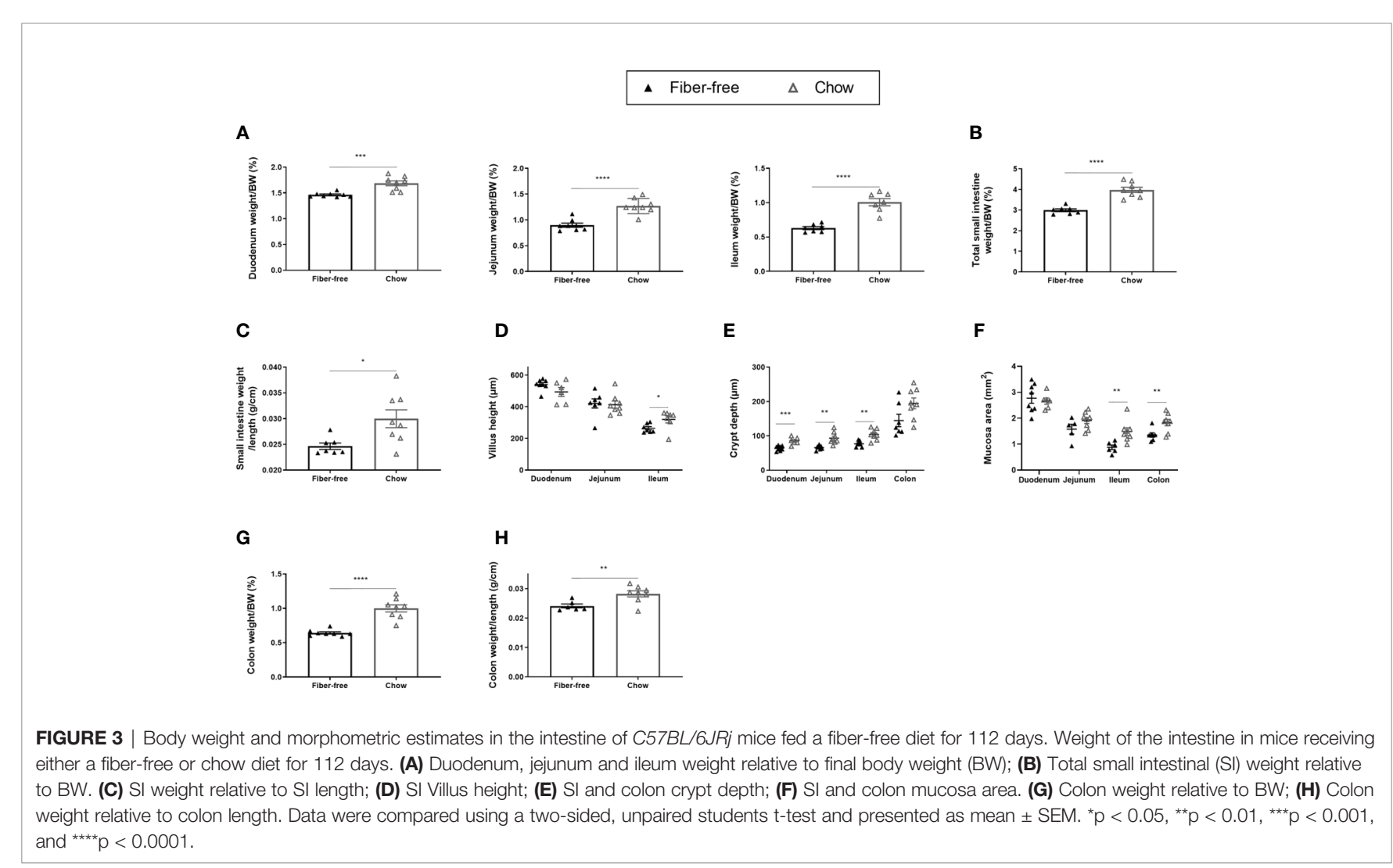




\section{Ileum}

A

GLP-1

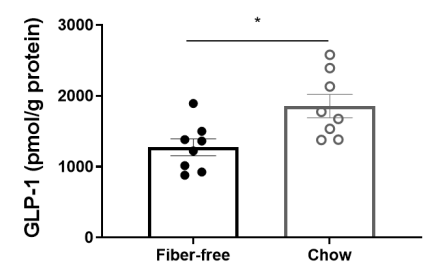

B

GLP-2

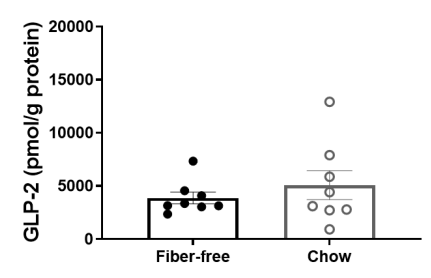

C

PYY

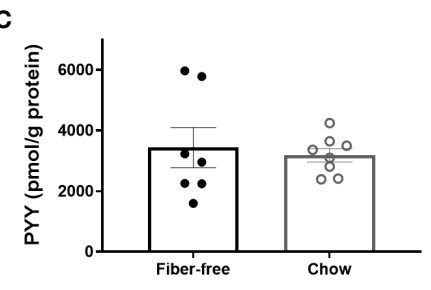

Colon
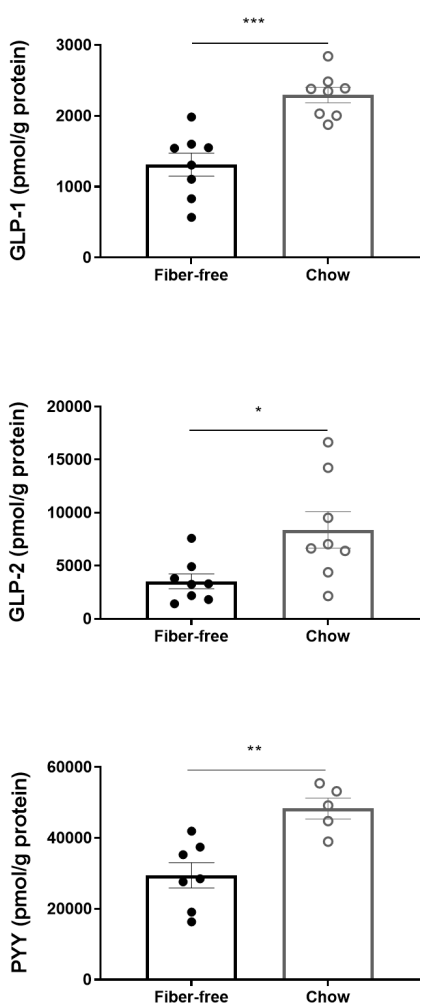

FIGURE 4 | L-cell hormone production in C57BL/6JRj mice fed a fiber-free diet for 21 days. L-cell hormone production in mice receiving either a fiber-free or chow diet for 21 days. (A) Total amidated GLP-1 (sum of intact GLP-1 (7-36)amide, the primary metabolite GLP-1 (9-36)amide and other GLP-1(x-36) amide isoforms) concentration, normalized to pmol per g protein, in the ileum and colonic tissue. (B) Intact GLP-2 (1-33) concentration normalized to pmol per $\mathrm{g}$ protein, in the ileum and colonic tissue. (C) Total PYY, sum of 1-36 and 3-36 isoforms, concentration, normalized to pmol per g protein, in the ileum and colonic tissue. Data were compared using a two-sided, unpaired students t-test and presented as mean $\pm \mathrm{SEM}$. ${ }^{\star} \mathrm{p} p<0.05,{ }^{\star \star} \mathrm{p}<0.01,{ }^{* \star} \mathrm{p} p<0.001$.
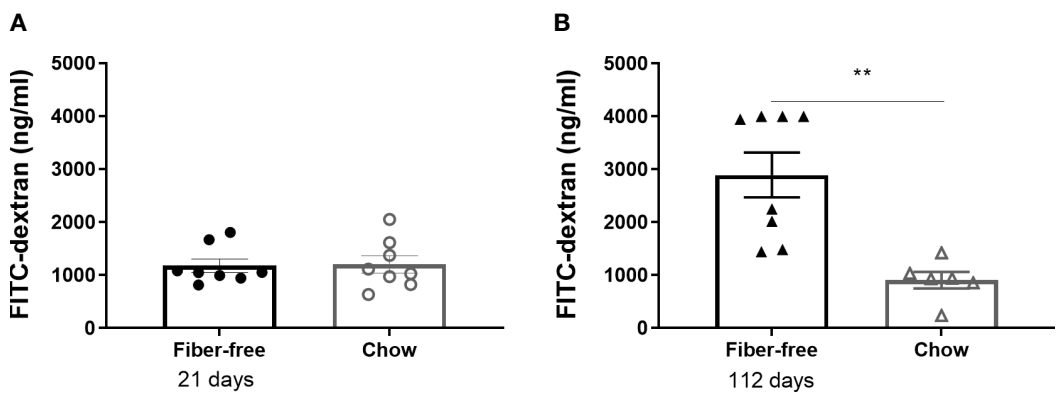

FIGURE 5 | Intestinal permeability in C57BL/6JRj mice fed a fiber-free diet for 21 and 112 days. Intestinal permeability in mice receiving either a fiber-free or chow diet (A) for 21 or (B) 112 days measured as the level of FITC-dextran in sera $2 \mathrm{~h}$ post oral administration. Data were compared using a two-sided, unpaired students t-test and presented as mean \pm SEM. ${ }^{* *} \mathrm{p}<0.01$.

unaffected following the 21 days deficient fiber feeding but was significantly increased after 112 days of feeding.

Traditionally, the physiological influence of dietary fiber was thought to be limited to the intestinal lumen, affecting gastric emptying rate (2), contributing to fecal bulk and moisture content (40). These attributes made fiber an ideal candidate to maintain healthy intestinal transit, yet increasingly fiber and its derivatives have been shown to play a role beyond lumen. 


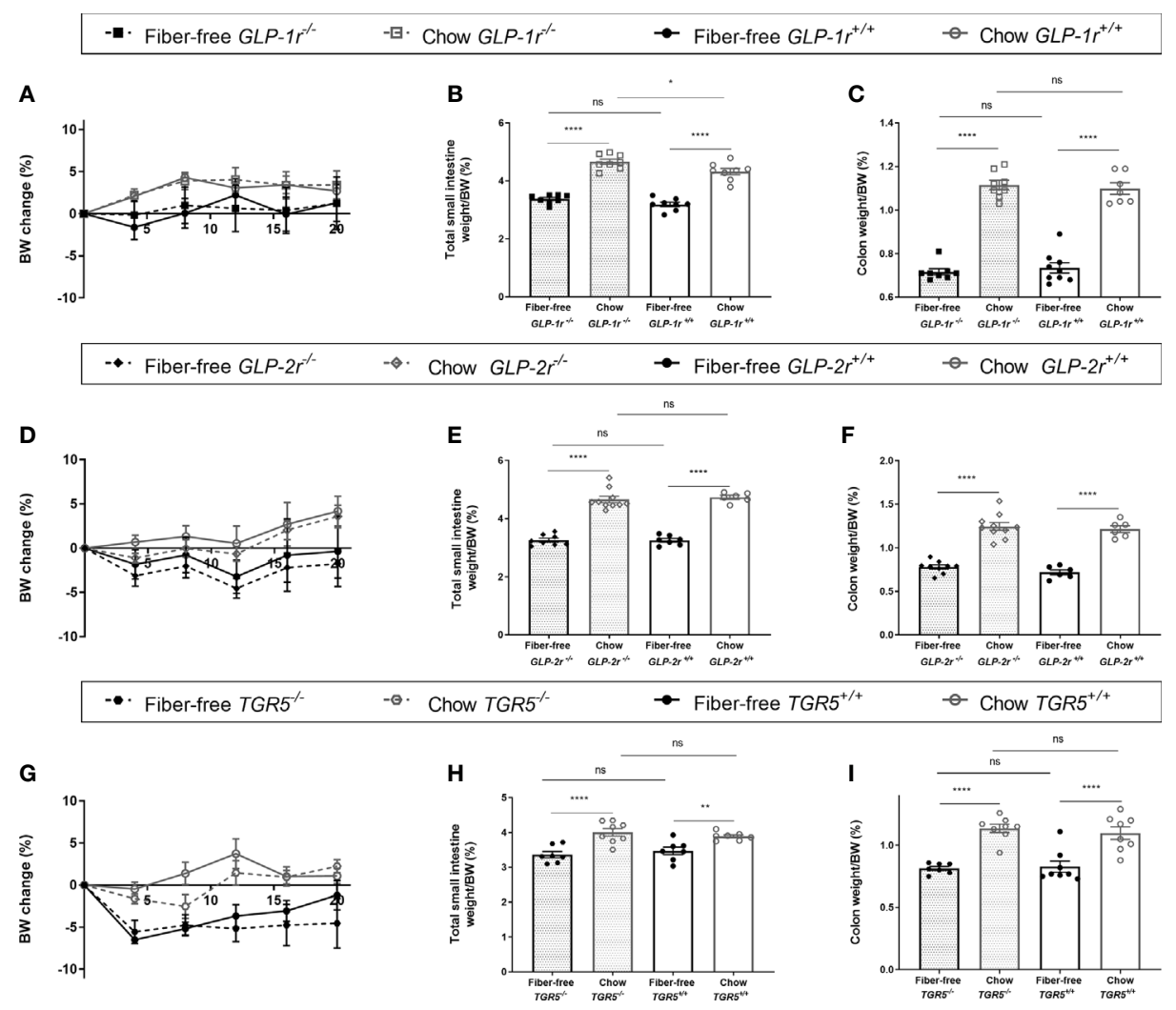

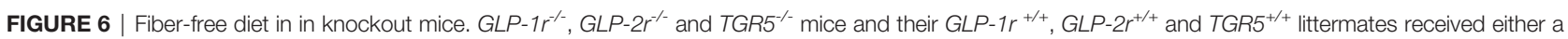
fiber-free or chow diet for 21 days. (A, D, G) Body weight (BW) change, expressed as percentage BW change; (B, E, H) Small intestinal (SI) weight, normalized to BW; (C, F, I) Colon weight normalized to BW. Data were compared using a two-way ANOVA followed by a Sidak's multiple comparisons test and data are presented as mean \pm SEM. ${ }^{\star \star} \mathrm{p}<0.01,{ }^{\star \star \star \star} \mathrm{p}<0.0001$ and $\mathrm{ns}$, non-significant.

Fiber has been shown to alter the physical characteristics of the rodent gut, such as increasing intestinal weight (41) and increasing intestinal epithelial cell proliferation (42), which could make fiber a potential candidate for ameliorating intestinal injury. These effects could also have implications for populations consuming low fiber diets such as part of a western diet or for patients following advice to consume low-fiber diets to alleviate intestinal side effects such as diarrhea (10).

To assess the impact of low fiber diets on the gut size, we switched mice from their normal chow diet to a fiber-deficient diet for 21 days. Here, we show that removal of crude dietary fiber significantly decreased the weight of the SI and, to a larger extent, the colon. Additionally, removal of fiber significantly decreased crypt depth in the SI and significantly decreased the mucosa area in the colon. These findings support previous data describing a dosedependent effect of fiber on gut size in rats (41). Similar to our study, the authors reported a fiber-mediated effect on crypt depth in the jejunum and ileum. Additionally, they report that fiber supplementation increased villus height whereas paradoxically we report a significant increase in villus height, in the duodenum, upon the removal of fiber after 21 days. This difference in outcome could be attributed to the different experimental setup, with Adam et al.
(41) supplementing diets with the soluble fiber pectin, compared to the total removal of crude fiber exemplified in this study. The total removal of fiber could trigger a compensatory response in the proximal SI due to a loss of absorptive capacity, as a product of reduced intestinal size.

We further investigated this possible compensatory response by repeating the experiment but with a long-term feeding schedule of 4 months (112 days). Comparable to the 21 days feeding regime, long-term fiber deficiency reduced SI and colon weights by a similar proportion that coincided with a decrease in crypt depth in the small intestine and a decrease in mucosa area in the colon. Uniquely in the long-term study, there was a decrease in villus height and overall mucosa area in the ileum following fiber-free feeding. These results suggest that the fiberfree fed mice were not able to compensate for their loss of intestinal weight over time. Instead, the reduction in crypt depth preceded villous atrophy in the ileum. At the cell level, atrophic loss may be a product of decreased proliferation or increased apoptosis. Here, we report no changes in proliferative activity measured using BrdU immunopositivity, therefore, it could be speculated that the atrophic loss was due to an increased apoptotic rate. 
The observed decrease in colonic weight could be assumed to be a product of the decreased fermentation processes, yet similar to previous findings utilizing soluble fiber in rats (41), the morphological changes were also present in the SI. This suggests that the observed growth effect was independent of the local actions of dietary fiber fermentation. Instead, we hypothesized the growth response in the SI could be mediated by the intestinal gut hormones GLP-1 and GLP-2. GLP-2 is a well-documented intestinal tropic hormone shown to increase proliferation and reduce apoptosis (16) (17) (43). GLP-1 can protect against mucosal loss following intestinal injury (44). Both hormones are co-secreted upon a number of nutritional stimuli including in response to dietary fiber fermentation products (22) (27). Indeed, we show that the absence of fiber in the diet decreased the tissue levels of GLP-1, GLP-2 and additionally PYY. The present results agree with previous studies assessing Lcell secretion following fiber supplement in rodents and humans (3) (45) (46). However, in contrast to measuring plasma hormone levels we measured the local tissue concentrations and showed that the L-cell hormones were primarily affected in the colon and to a lesser extent in the distal SI. This ultimately suggests that the fiber-mediated stimulation of the gut growth is controlled by colonic L-cells. Targeting this colonic endocrine function has a large therapeutic potential since the largest density of L-cells is found in the colon (47). These L-cells are situated away from classical luminal nutrient stimulation thereby attributing a different source of stimuli for this subset of L-cells that we are just beginning to characterize.

Given that a decrease in intestinal size corresponded with a decrease in L-cell content in the colon following a fiber deficient diet, we hypothesized that the intestinotrophic actions of GLP-2 and to a lesser extent GLP-1 could drive this response and investigated our hypothesis using global

GLP- $1 r^{-/-}$and GLP-2r-/- mice. Abolition of GLP-1 receptor signaling did not affect the decreased SI or colon weight observed following deficient dietary fiber feeding; however, loss of fiber from the diet removed the significant increase in SI weight observed in GLP-1 $r^{-/-}$mice. This suggests an interaction between GLP-1 signaling, gut size and the presence of fiber, whereby in the presence of fiber, GLP-1 $r^{-/-}$mice develop increased SI weight, while the signal is lost following the removal of fiber. Abolition of GLP-2 receptor signaling did not affect the intestinal size. To assess if the growth response could be impacted by the indirect manipulation of GLP-1 and GLP-2 we used the bile acid receptor TGR5 $5^{-/-}$mice. TGR5 is located on the L-cell and we have previously shown that TGR5 stimulation led to a GLP-2 mediated increase in intestinal size from colonic Lcells (33). However, in the current experiments intestinal size was not impacted by TGR5 signaling. Therefore, we were not able to show the mechanistic drivers of the fiber-mediated growth response using these knockout mouse models. Future studies should focus on assessing the contribution of other microbial modulated metabolites or by assessing receptor contributions in inducible knockout models since germline knockout models, as used in this study, are limited by the risk of evolved compensatory mechanisms to maintain their intestinal capacity.
Dietary fiber has been proposed to improve gut and overall health by helping maintain the intestinal barrier $(4,48)$. Upon the removal of dietary fiber, bacteria switch their glycan metabolism from fiber degradation to mucus glycan degradation thereby reducing the colonic mucus layer thickness which increases microbial translocation, triggering systemic inflammation $(4,48$, 49). Here, we investigated intestinal permeability following the removal of dietary fiber using FITC-dextran. Surprisingly, there were no differences in permeability after 21 days but a large increase after 112 days of fiber-free feeding. This suggests that long-term fiber interventions are required to moderate permeability to an extent that can be detected at the serum level but does not rule out short-term precursor modifications such as mucus layer thickness, which were not assessed in this study.

The present study is limited by a difference in the composition of the two compared diets. Both diets were purchased from the same distributor but had micro and macronutrient differences beyond the content of fiber including a higher $\mathrm{kcal} / \mathrm{kg}$ in the fiber-free diet. Likely due to the higher $\mathrm{kcal} / \mathrm{kg}$, fiber-free fed mice consumed less diet which at the end of the 21 day feeding period increased the disparities between macronutrient consumption and led to a significant decrease in BW from day 8. In particular, after 21 days the fiber-free mice had consumed less protein compared to the chow mice ( 8 vs. $13 \mathrm{~g}$ ) therefore, we cannot exclude the influence of decreased protein in the investigated intestinal parameters. Despite this, previous studies investigating the effect of low protein diets on the intestine have shown they correlate with a significant reduction in villus heights $(50,51)$ which was not observed in our study. Additionally, protein diets have been shown to have little effect on the GLP-2 secretion (52).

Despite the numerous studies describing the health benefits of dietary fiber consumption in humans, the doses needed to emulate the benefits are often not realized in practice due to a combination of logistical reasons affecting compliance and adverse effects such as bloating (53) and flatulence (54). Therefore, it remains important to investigate the mechanisms behind these health benefits to develop dietary recommendations to yield new approaches to prevent or treat a range of human diseases. Here, we show that fiber is essential to maintain intestinal size, colonic L-cell hormone levels and maintain intestinal integrity. These findings could have important implications for populations consuming low-fiber diets such as part of a western diet, who could have an increased susceptibility to intestinal disease. In particular, patients recommended to consume low-fiber diets following intestinal injury, such as in the case of pelvic radiotherapy (55), could be at particular risk since despite the low-fiber diet improving intestinal side effects such as diarrhea, simultaneously it might prolong the radiationinduced intestinal damage (56). Despite showing here that a deficient fiber status dramatically altered the colonic endocrine function, the mechanistic drivers of this response were not elucidated. The spatiotemporal location of the colonic endocrine cells implicates alternative stimuli to classical luminal nutrients such as microbially modulated metabolites like SCFA that are produced and bile acids that are modified and by bacteria-driven processes. Given this, future fiber mediated 
metabolomics studies are necessary to define likely candidates of L-cell secretion in the colon.

\section{DATA AVAILABILITY STATEMENT}

The original contributions presented in the study are included in the article/Supplementary Material. Further inquiries can be directed to the corresponding author.

\section{ETHICS STATEMENT}

The animal studies were reviewed and approved by the Danish animal experiments inspectorate.

\section{AUTHOR CONTRIBUTIONS}

JEH and HK planned and designed the study. KS provided analytical material. JEH and HK performed the experiments. $\mathrm{JEH}$ and $\mathrm{BH}$ analyzed the results and JEH and $\mathrm{HK}$ interpreted

\section{REFERENCES}

1. Reynolds A, Mann J, Cummings J, Winter N, Mete E, Te Morenga L. Carbohydrate quality and human health: a series of systematic reviews and meta-analyses. Lancet (2019) 393:434-45. doi: 10.1016/S0140-6736(18)31809-9

2. Benini L, Castellani G, Brighenti F, Heaton KW, Brentegani MT, Casiraghi MC, et al. Gastric emptying of a solid meal is accelerated by the removal of dietary fibre naturally present in food. Gut (1995) 36:825-30. doi: 10.1136/gut.36.6.825

3. Delmée E, Cani PD, Gual G, Knauf C, Burcelin R, Maton N, et al. Relation between colonic proglucagon expression and metabolic response to oligofructose in high fat diet-fed mice. Life Sci (2006) 79:1007-13. doi: 10.1016/j.lfs.2006.05.013

4. Desai MS, Seekatz AM, Koropatkin NM, Kamada N, Hickey CA, Wolter M, et al. A Dietary Fiber-Deprived Gut Microbiota Degrades the Colonic Mucus Barrier and Enhances Pathogen Susceptibility. Cell (2016) 167:1339-1353.e21. doi: 10.1016/j.cell.2016.10.043

5. Makki K, Deehan EC, Walter J, Bäckhed F. The Impact of Dietary Fiber on Gut Microbiota in Host Health and Disease. Cell Host Microbe (2018) 23:70515. doi: 10.1016/j.chom.2018.05.012

6. CDC/National Center for Health Statistics. National Health and Nutrition Examination Survey NHANES 2013-2014 Dietary Data. www.CDC.gov. (2016). Available at: https://wwwn.cdc.gov/nchs/nhanes/search/datapage. aspx?Component=Dietary\&CycleBeginYear=2013.

7. Statovci D, Aguilera M, MacSharry J, Melgar S. The impact of western diet and nutrients on the microbiota and immune response at mucosal interfaces. Front Immunol (2017) 8:838. doi: 10.3389/fimmu.2017.00838

8. Sonnenburg ED, Smits SA, Tikhonov M, Higginbottom SK, Wingreen NS, Sonnenburg JL. Diet-induced extinction in the gut microbiota compounds over generations. Nature (2016) 529:212-5. doi: 10.1007/BF00376045

9. Schnorr SL, Candela M, Rampelli S, Centanni M, Consolandi C, Basaglia G, et al. Gut microbiome of the Hadza hunter-gatherers. Nat Commun (2014) 5:3654. doi: $10.1038 /$ ncomms4654

10. Vanhauwaert E, Matthys C, Verdonck L, de Preter V. Low-residue and lowfiber diets in gastrointestinal disease management. Adv Nutr (2015) 6:820-7. doi: 10.3945/an.115.009688

11. Bodnaruc AM, Prud'homme D, Blanchet R, Giroux I. Nutritional modulation of endogenous glucagon-like peptide-1 secretion: a review. Nutr Metab (Lond) (2016) 13:92. doi: 10.1186/s12986-016-0153-3 the results of the experiment. JEH drafted the manuscript. JEH, $\mathrm{JJH}$, and $\mathrm{HK}$ critically revised and edited the manuscript. All authors contributed to the article and approved the submitted version.

\section{FUNDING}

This work was supported by the Lundbeck Foundation (Grant No. R263-2017-3740), Dagmar Marshall foundation, Aase og Ejnar Danielsens Fond, Agnes og Poul Friis fond, Læge Sofus Carl Emil Friis og Hustru Olga Doris Friis' Legat and was supported by the Novo Nordisk Foundation Center for Basic Metabolic Research (Novo Nordisk Foundation, Denmark).

\section{SUPPLEMENTARY MATERIAL}

The Supplementary Material for this article can be found online at: https://www.frontiersin.org/articles/10.3389/fendo.2021. 640602/full\#supplementary-material

12. Baldassano S, Amato A, Cappello F, Rappa F, Mulè F. Glucagon-like peptide-2 and mouse intestinal adaptation to a high-fat diet. J Endocrinol (2013) 217:1120. doi: 10.1530/JOE-12-0500

13. Nauck MA, Homberger E, Siegel EG, Allen RC, Eaton PR, Ebert R, et al. Incretin Effects of Increasing Glucose Loads in Man Calculated from Venous Insulin and C-Peptide Responses. J Clin Endocrinol Metab (1986) 63:492-8. doi: 10.1210/jcem-63-2-492

14. Kissow H, Hartmann B, Holst JJ, Viby NE, Hansen LS, Rosenkilde MM, et al. Glucagon-like peptide-1 (GLP-1) receptor agonism or DPP-4 inhibition does not accelerate neoplasia in carcinogen treated mice. Regul Pept (2012) 179:91100. doi: 10.1016/j.regpep.2012.08.016

15. Simonsen L, Pilgaard S, Orskov C, Rosenkilde MM, Hartmann B, Holst JJ, et al. Exendin-4, but not dipeptidyl peptidase IV inhibition, increases small intestinal mass in GK rats. Am J Physiol - Gastrointest Liver Physiol (2007) 293:288-95. doi: 10.1152/ajpgi.00453.2006

16. Drucker DJ, Ehrlich P, Asat SL, Brubaker PL. Induction of intestinal epithelial proliferation by glucagon-like peptide 2. Proc Natl Acad Sci (1996) 93:7911-6. doi: 10.1073/pnas.93.15.7911

17. Shin ED, Estall JL, Izzo A, Drucker DJ, Brubaker PL. Mucosal adaptation to enteral nutrients is dependent on the physiologic actions of glucagon-like peptide-2 in mice. Gastroenterology (2005) 128:1340-53. doi: 10.1053/ j.gastro.2005.02.033

18. Xiao Q, Boushey RP, Cino M, Drucker DJ, Brubaker PL. Circulating levels of glucagon-like peptide-2 in human subjects with inflammatory bowel disease. Am J Physiol - Regul Integr Comp Physiol (2000) 278:1057-63. doi: 10.1152/ ajpregu.2000.278.4.r1057

19. Kissow H, Viby NE, Hartmann B, Holst JJ, Timm M, Thim L, et al. Exogenous glucagon-like peptide-2 (GLP-2) prevents chemotherapy-induced mucositis in rat small intestine. Cancer Chemother Pharmacol (2012) 70:39-48. doi: 10.1007/s00280-012-1882-2

20. Hytting-Andreasen R, Balk-Møller E, Hartmann B, Pedersen J, Windeløv JA, Holst JJ, et al. Endogenous glucagon-like peptide- 1 and 2 are essential for regeneration after acute intestinal injury in mice. PloS One (2018) 13:1-14. doi: 10.1371/journal.pone.0198046

21. Elliott RM, Wright J. Glucagon-like peptide-1 (7-36)amide and glucosedependent insulinotropic polypeptide secretion in response to nutrient ingestion in man: acute post-prandial and 24-h secretion patterns. J Endocrinol (1993) 138:159-66. doi: 10.1677/joe.0.1380159 
22. Christiansen CB, Gabe MBN, Svendsen B, Dragsted LO, Rosenkilde MM, Holst JJ. The impact of short-chain fatty acids on glp-1 and pyy secretion from the isolated perfused rat colon. Am J Physiol - Gastrointest Liver Physiol (2018) 315:G53-65. doi: 10.1152/ajpgi.00346.2017

23. Christiansen CB, Trammell SAJ, Albrechtsen NJW, Schoonjans K, Albrechtsen R, Gillum MP, et al. Bile acids drive colonic secretion of glucagon-like-peptide 1 and peptide-YY in rodents. Am J Physiol Gastrointest Liver Physiol (2019) 316:G574-84. doi: 10.1152/ajpgi.00010.2019

24. Wu T, Bound MJ, Standfield SD, Gedulin B, Jones KL, Horowitz M, et al. Effects of rectal administration of taurocholic acid on glucagon-like peptide-1 and peptide YY secretion in healthy humans. Diabetes Obes Metab (2013) 15:474-7. doi: 10.1111/dom.12043

25. Canfora EE, Van Der Beek CM, Jocken JWE, Goossens GH, Holst JJ, Olde Damink SWM, et al. Colonic infusions of short-chain fatty acid mixtures promote energy metabolism in overweight/obese men: A randomized crossover trial. Sci Rep (2017) 7:2360. doi: 10.1038/s41598-017-02546-x

26. Topping DL, Clifton PM. Short-chain fatty acids and human colonic function: Roles of resistant starch and nonstarch polysaccharides. Physiol Rev (2001) 81:1031-64. doi: 10.1152/physrev.2001.81.3.1031

27. Tolhurst G, Heffron H, Shan Lam Y, Parker HE, Habib AM, Diakogiannaki E, et al. Short-Chain Fatty Acids Stimulate Glucagon-Like Peptide-1 Secretion via the G protein- Coupled Receptor FFAR2. Diabetes (2012) 61:364. doi: 10.2337/db11-1019

28. Nøhr MK, Pedersen MH, Gille A, Egerod KL, Engelstoft MS, Husted AS, et al. GPR41/FFAR3 and GPR43/FFAR2 as cosensors for short-chain fatty acids in enteroendocrine cells vs FFAR3 in enteric neurons and FFAR2 in enteric leukocytes. Endocrinology (2013) 154:3552-64. doi: 10.1210/en.2013-1142

29. Sayin SI, Wahlström A, Felin J, Jäntti S, Marschall HU, Bamberg K, et al. Gut microbiota regulates bile acid metabolism by reducing the levels of tauro-betamuricholic acid, a naturally occurring FXR antagonist. Cell Metab (2013) 17:225-35. doi: 10.1016/j.cmet.2013.01.003

30. Wahlström A, Sayin SI, Marschall HU, Bäckhed F. Intestinal Crosstalk between Bile Acids and Microbiota and Its Impact on Host Metabolism. Cell Metab (2016) 24:41-50. doi: 10.1016/j.cmet.2016.05.005

31. Kuhre RE, Wewer Albrechtsen NJ, Larsen O, Jepsen SL, Balk-Møller E, Andersen $\mathrm{DB}$, et al. Bile acids are important direct and indirect regulators of the secretion of appetite- and metabolism-regulating hormones from the gut and pancreas. Mol Metab (2018) 11:84-95. doi: 10.1016/j.molmet.2018.03.007

32. Agerlin E, Svendsen, Balk-Møller E, Windeløv J, Hunt J, Mojtaba SG, et al. Glucagon-like peptide 1 and atrial natriuretic peptide in a female mouse model of obstructive pulmonary disease. J Endocr Soc (2019) 4:bvz034. doi: $10.1210 /$ jendso/bvz034

33. Hunt JE, Billeschou A, Windeløv JA, Hartmann B, Ullmer C, Holst JJ, et al. Pharmacological activation of TGR5 promotes intestinal growth via a GLP-2 dependent pathway in mice. Am J Physiol Liver Physiol (2020) 318:980-7. doi: 10.1152 /ajpgi.00062.2020

34. Thomas C, Gioiello A, Noriega L, Strehle A, Oury J, Rizzo G, et al. TGR5mediated bile acid sensing controls glucose homeostasis. Cell Metab (2009) 10:167-77. doi: 10.1016/j.cmet.2009.08.001.TGR5-mediated

35. Billeschou A, Hunt J, Kissow H. Important Endpoints and Proliferative Markers to Assess Small Intestinal Injury and Adaptation using a Mouse Model of Chemotherapy-Induced Mucositis. J Vis Exp (2019) 147. doi: 10.3791/59236

36. Orskov C, Rabenhøj L, Wettergren A, Kofod H, Holst JJ. Tissue and plasma concentrations of amidated and glycine-extended glucagon-like peptide I in humans. Diabetes (1994) 43:535-9. doi: 10.2337/diabetes.43.4.535

37. Hartmann B, Johnsen AH, Ørskov C, Adelhorst K, Thim L, Holst JJ. Structure, measurement, and secretion of human glucagon-like peptide-2. Peptides (2000) 21:73-80. doi: 10.1016/S0196-9781(99)00176-X

38. Svendsen B, Pedersen J, Albrechtsen NJW, Hartmann B, Toräng S, Rehfeld JF, et al. An analysis of cosecretion and coexpression of gut hormones from male rat proximal and distal small intestine. Endocrinology (2015) 156:847-57. doi: 10.1210/en.2014-1710

39. Woting A, Blaut M. Small intestinal permeability and gut-transit time determined with low and high molecular weight fluorescein isothiocyanatedextrans in C3H mice. Nutrients (2018) 10:4-10. doi: 10.3390/nu10060685

40. de Vries J, Miller PE, Verbeke K. Effects of cereal fiber on bowel function: A systematic review of intervention trials. World J Gastroenterol (2015) 21:895263. doi: $10.3748 /$ wjg.v21.i29.8952
41. Adam CL, Williams PA, Garden KE, Thomson LM, Ross AW. Dosedependent effects of a soluble dietary fibre (pectin) on food intake, adiposity, gut hypertrophy and gut satiety hormone secretion in rats. PloS One (2015) 10:1-14. doi: 10.1371/journal.pone.0115438

42. Goodlad RA, Ratcliffe B, Fordham JP, Wright NA. Does dietary fibre stimulate intestinal epithelial cell proliferation in germ free rats? Gut (1989) 30:820-5. doi: 10.1136/gut.30.6.820

43. Tsai C, Hill M, Asa SL, Brubaker PL, Druckeri J. Intestinal growth-promoting properties of glucagon-like peptide-2 in mice. Am J Physiol (1997) 273:E7784. doi: 10.1152/ajpendo.1997.273.1.E77

44. Kissow H, Hartmann B, Holst JJ, Poulsen SS. Glucagon-like peptide-1 as a treatment for chemotherapy-induced mucositis. Gut (2013) 62:1724-33. doi: 10.1136/gutjnl-2012-303280

45. Keenan MJ, Zhou J, McCutcheon KL, Raggio AM, Bateman HG, Todd E, et al. Effects of resistant starch, a non-digestible fermentable fiber, on reducing body fat. Obesity (2006) 14:1523-34. doi: 10.1038/oby.2006.176

46. Zhao L, Zhang F, Ding X, Wu G, Lam YY, Shi Y, et al. Gut bacteria selectively promoted by dietary fibers alleviate type 2 diabetes. Sci (2018) 359:1151-6. doi: $10.1126 /$ science.aao5774

47. Eissele R, Göke R, Willemer S, Harthus H, Vermeer H, Arnold R, et al. Glucagon-like peptide-1 cells in the gastrointestinal tract and pancreas of rat, pig and man. Eur J Clin Invest (1992) 22:283-91. doi: 10.1111/j.13652362.1992.tb01464.x

48. Schroeder BO, Birchenough GMH, Ståhlman M, Arike L, Johansson MEV, Hansson GC, et al. Bifidobacteria or fiber protect against diet-induced microbiota-mediated colonic mucus deterioration HHS Public Access The defects can be prevented by application of a probiotic bifidobacteria or the prebiotic fiber inulin. Cell Host Microbe (2018) 23:27-40. doi: 10.1016/ j.chom.2017.11.004

49. Rizzetto L, Fava F, Tuohy KM, Selmi C. Connecting the immune system, systemic chronic inflammation and the gut microbiome: The role of sex. J Autoimmun (2018) 92:12-34. doi: 10.1016/j.jaut.2018.05.008

50. Laudadio V, Passantino L, Perillo A, Lopresti G, Passantino A, Khan RU, et al. Productive performance and histological features of intestinal mucosa of broiler chickens fed different dietary protein levels. Poult Sci (2012) 91:265-70. doi: 10.3382/ps.2011-01675

51. Chen X, Song P, Fan P, He T, Jacobs D, Levesque CL, et al. Moderate dietary protein restriction optimized gut microbiota and mucosal barrier in growing pig model. Front Cell Infect Microbiol (2018) 8:246. doi: 10.3389/fcimb.2018.00246

52. Xiao Q, Boushey RP, Drucker DJ, Brubaker PL. Secretion of the Intestinotropic Hormone Glucagon-like Peptide 2 Is Differentially Regulated by Nutrients in Humans. Gastroenterology (1999) 117:99-105. doi: 10.1016/S0016-5085(99)70555-X

53. Gonlachanvit S, Coleski R, Owyang C, Hasler WL. Inhibitory actions of a high fibre diet on intestinal gas transit in healthy volunteers. Gut (2004) 53:157782. doi: 10.1136 /gut.2004.041632

54. Tomlin J, Lowis C, Read NW. Investigation of normal flatus production in healthy volunteers. Gut (1991) 32:665-9. doi: 10.1136/gut.32.6.665

55. Malipatlolla DK, Patel P, Sjöberg F, Devarakonda S, Kalm M, Angenete E, et al. Long-term mucosal injury and repair in a murine model of pelvic radiotherapy. Sci Rep (2019) 9:4-13. doi: 10.1038/s41598-019-50023-4

56. Ahlin R, Sjöberg F, Bull C, Steineck G, Hedelin M. Stor variation i kostråden vid strålbehandling av lilla bäckenet - Kost har potential att förebygga följdsjukdomar till strålning och ge bättre tarmhälsa - men vetenskaplig evidens saknas [Differing dietary advice are given to gynaecological and prostate cancer patients receiving radiotherapy in Sweden]. Lakartidningen (2018) 115.

Conflict of Interest: The authors declare that the research was conducted in the absence of any commercial or financial relationships that could be construed as a potential conflict of interest.

Copyright $\odot 2021$ Hunt, Hartmann, Schoonjans, Holst and Kissow. This is an openaccess article distributed under the terms of the Creative Commons Attribution License (CC BY). The use, distribution or reproduction in other forums is permitted, provided the original author(s) and the copyright owner(s) are credited and that the original publication in this journal is cited, in accordance with accepted academic practice. No use, distribution or reproduction is permitted which does not comply with these terms. 